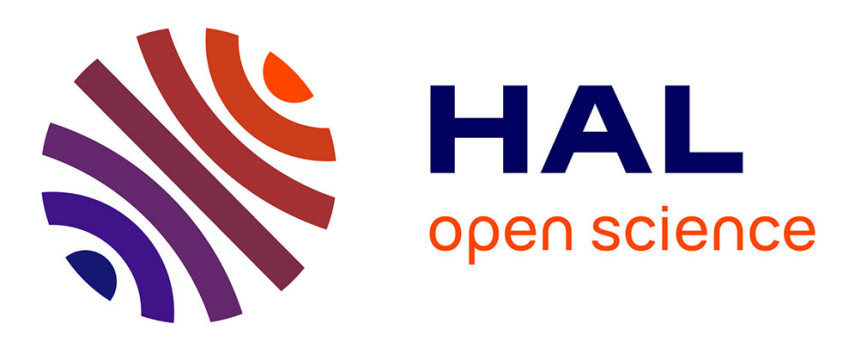

\title{
Probability density functions: From porosities to fatigue lifetime
}

Eric Charkaluk, Andrei Constantinescu, Fabien Szmytka, Shadan Tabibian

\section{To cite this version:}

Eric Charkaluk, Andrei Constantinescu, Fabien Szmytka, Shadan Tabibian. Probability density functions: From porosities to fatigue lifetime. International Journal of Fatigue, 2014, 63, pp.127-136. 10.1016/j.ijfatigue.2014.01.017 . hal-00961217

\section{HAL Id: hal-00961217 https://hal.science/hal-00961217}

Submitted on 1 Jun 2021

HAL is a multi-disciplinary open access archive for the deposit and dissemination of scientific research documents, whether they are published or not. The documents may come from teaching and research institutions in France or abroad, or from public or private research centers.
L'archive ouverte pluridisciplinaire HAL, est destinée au dépôt et à la diffusion de documents scientifiques de niveau recherche, publiés ou non, émanant des établissements d'enseignement et de recherche français ou étrangers, des laboratoires publics ou privés.

\section{(c)(1)}

Distributed under a Creative Commons Attribution| 4.0 International License 


\title{
Probability density functions: From porosities to fatigue lifetime
}

\author{
E. Charkaluk ${ }^{\mathrm{b}}$, A. Constantinescu ${ }^{\text {c,* }}$, F. Szmytka a ${ }^{\text {, S. Tabibian }}{ }^{\mathrm{a}, \mathrm{b}, \mathrm{c}}$
}

\begin{abstract}
a Automotive Research and Innovation Division, PSA Peugeot Citroën, Route de Gisy, Vélizy-Villacoublay 78943, France ${ }^{\mathrm{b}}$ LML, CNRS UMR 8107, Laboratoire Mécanique de Lille, Ecole Centrale de Lille, Cité Scientifique, 59650 Villeneuve d'Ascq, France ${ }^{c}$ LMS, CNRS UMR 7649, Laboratoire Mécanique Solides, Ecole Polytechnique, Route Saclay, 91120 Palaiseau, France
\end{abstract}

\begin{abstract}
This paper proposes a novel method to establish and identify a probability density function characterizing the fatigue lifetime. The method is initiated with a quantitative analysis of the microstructure of the material, which provides the initial probability distribution of defects. After identifying a given probability density function of defects, one can transport it into a lifetime probability density function using a growth law involving a measure of the loading over a cycle. Several parameters of the growth law are finally estimated from a given set of fatigue experiments on specimens and several techniques are discussed. The method is applied on real defect observations and lifetime data. The estimated lifetimes using the novel technique is of similar quality with standard estimation providing the probability density function of lifetime as an additional output. This output can be used directly as an input in a stress-strength interference method.
\end{abstract}

\section{Introduction}

The search for performance in lightweight and environmentally-friendly structures leads automotive companies to choose aluminum alloys as the preferred material for engine parts like pistons, cylinder blocks and cylinder heads. Among aluminum alloys, the A3XX series which contains components like silicon, magnesium and/or copper is commonly used due to its high strength to weight ratio, good machinability, corrosion resistance, optimum surface finish as well as its high thermal conductivity [1]. In the $3 x x$ series, the A356 alloy is the preferred choice due to its enhanced tensile strength after heat treatment. Another popular choice for the manufacturing of cylinder heads and engine blocks is the A319, due to its excellent casting characteristics. The later also associates good mechanical properties to low cost component production, crucial energy efficiency and concomitant environmental benefits $[2,3]$.

Cylinder heads have become one of the critical components during the last years in the engine design process, due to the increase of in-service temperatures combined to the mass decrease imposed by the environmental constraints. The main concern of the cylinder head is thermomechanical fatigue (TMF) as mentioned in a series of papers in the last decades [4-7]. The die casting process (DC) was commonly used to produce cylinder heads but has

* Corresponding author. Tel.: +3316933 5756 .

E-mail addresses: eric.charkaluk@ec-lille.fr (E. Charkaluk), andrei.constantinescu@ Ims.polytechnique.fr (A. Constantinescu), fabien.szmytka@mpsa.com (F. Szmytka), shadan_tabibian@yahoo.com (S. Tabibian). been recently often replaced with the Lost Foam Casting (LFC) process. Indeed, if the die casting process produces geometrically complex metal parts through the use of reusable molds, Lost Foam Casting permits to further reduce process cost and participates to the weight reduction goals by permitting much more degree of freedom (smaller radius in the geometries, complex shape, etc.). However Lost Foam Casting comes with a considerable change in the microstructure of the material. The major specificity of this process is indeed its relatively slow cooling rate when compared to the die casting process, i.e. $0.8^{\circ} \mathrm{C} / \mathrm{s}$ compared to $30^{\circ} \mathrm{C} / \mathrm{s}$ respectively [8]. The difference in cooling rate creates a coarser microstructure when measured in term of Dendrite Arm Spacing (DAS) or LFC alloys. Besides, residual porosity and inclusions (intermetallics, oxides), formed during the degradation of the polymeric pattern $[9,10]$, are increased and clustered. Even if these phenomena do not reduce the overall mechanical properties of the material, they have an important impact on lifetime of components during in-service loadings.

Lifetime assessment of structures subjected to TMF is often a complex process due to the diversity and complexity of the involved mechanisms: plasticity, viscosity, microcrack propagation, etc. In spite of important advances in the field, the expressions of TMF criteria remain phenomenological and rarely take into account of the underlying microstructure. For instance, Weick and Aktaa [11] and Yamauchi et al. [12] analyzed a series of isothermal biaxial and thermal strain-controlled tests, respectively, which were conducted on tubular samples and proposed modified versions of the Manson-Coffin Low Cycle Fatigue criterion. Zouani et al. [13] developed an isothermal biaxial stress controlled 


\section{Nomenclature}

a defect size

$p_{a} \quad$ probability density function describing the defect size $a$

$p_{F} \quad$ probability density function describing the failure probability at cycle $N_{F}$

$\widehat{\mu} \quad$ mean value of a probability density function

$\hat{\sigma} \quad$ standard deviation of a probability density function fatigue parameter, i.e. function describing the size of the shakedown cycle stress strain dissipated energy per cycle hydrostatic stress experiment carried out on a particular circular sample and proposed a modified Morrow criterion. Other examples can be found in Socie and Fatemi $[14,15]$. Moreover, the extensions of Chaboche's initial formulation based on continuum damage mechanics $[5,16,17]$ and energy-based formulations $[18,19]$ could also be cited. Modifications of fatigue criteria based on the dissipated energy per cycle were also proposed for example in Park and Nelson [20] and in a series of papers by Amiable et al. [21,22]. The proposal by Amiable et al. [21] includes the maximal hydrostatic stress in the modification and has been recently compared with other criteria on steel in Fissolo et al. [23-25]. In the automotive industry, numerous phenomenological contributions in TMF lifetime assessment could also be found especially for aluminum alloys $[5,17,26,18]$ and a recent comparison of some TMF criteria in [27] for LFC alloys. In spite of the recent development, there is still demand to better link between lifetime and the material microstructure. The objective of this paper to propose a step in this direction, by relating the variability of the microstructure with the one of lifetimes.

This article discusses in a first part a quantitative analysis of the microstructure of the A319 LFC alloy in terms of porosity. The analysis is based on Scanning Electron Microscopy (SEM) observations and digital postprocessing. The observed statistical distribution of porosities and intermetallics are then represented using different probability density functions. This initial distribution of defects, porosities and intermetallics are assumed to represent the precursors to the initiation of microcracks and as such affect the fatigue lifetime. In the second part, starting from the distributions of defects a fatigue lifetime prediction model is proposed. The model includes both micro-initiation and micro-propagation and provides both a standard fatigue life estimation and a probability density as a function of a damage parameter and the number of cycles to failure. Two different optimization schemes are used for the identification of the parameters in the fatigue model. Both are presented and their physical signification is discussed. The robustness of the model is discussed on TMF data for an A319 aluminum alloy.

\section{Experimental database}

The material studied in this paper is an aluminum-silicon alloy widely used in the automotive industry, A319, without heat treatment and obtained by a LFC process. Its chemical composition is given in Table 1. The exposure of this alloy at high temperature (above $150{ }^{\circ} \mathrm{C}$ ) leads to a modification of its microstructure and mechanical properties as already discussed in [28,29]. Let us remark that the TMF of engine parts, defined as the initiation of visible cracks often occurs in regions of high temperature. In these regions microstructure and fatigue resistance are altered by the long term high temperature exposure, also denoted as "overaging". Moreover, over-aging corresponds to a stabilization of both mechanical properties and microstructure under a long term exposure of the material to high temperature. In the present case, over-aging corresponds to an exposure of $200 \mathrm{~h}$ at $250^{\circ} \mathrm{C}$. As a consequence TMF criteria discussed next are built from experiments done on over-aged materials.

The thermomechanical fatigue behavior is estimated from strain-controlled Low Cycle Fatigue tests on over-aged specimens. The experimental database considered here consists of 35 tests, performed with a strain ratio $R_{\varepsilon}=-1$. Temperatures, strain and number of cycles to failure ranges are detailed in Table 2. All tests were conducted with a mechanical strain rate of $\dot{\varepsilon}=10^{-3} \mathrm{~s}^{-1}$.

\section{Quantitative analysis of microstructure}

\subsection{SEM observations analysis}

The basic microstructure of the studied A319-LFC alloy consists of $\mathrm{Al}-\mathrm{Si}$ eutectics, Iron containing $\alpha$-AlFeSi $\left(\mathrm{Al}_{15} \mathrm{Fe}_{3} \mathrm{Mn}_{3} \mathrm{Si}_{2}\right)$ and $\beta$-AlFeSi $\left(\mathrm{Al}_{5} \mathrm{FeSi}\right)$ phases and Copper based eutectic $\theta-\mathrm{Al}-\mathrm{Al}_{2}$ $\mathrm{Cu}$ phases (see Tabibian et al. [29] for further details). Although all components may play a role in the microstructural damage mechanisms leading to fatigue, we assume that main role is played by the porosity in the cases studied next. This assumption is justified by the observation that micro-shrinkage zones are preferential initiation sites in terms of thermomechanical fatigue, due to their morphology. Therefore, only the statistical distribution of these microstructural defects will be discussed in the sequel.

Several material specimens extracted from fire decks of LFC cylinder heads have been analyzed by scanning electron microscopy (SEM). The obtained images were processed using the ImageJ software (http://rsb.info.nih.gov/ij/) following a precise procedure for counting the number and measuring the size of the pores. The evolution of the images obtained during the different steps of the image processing procedure are displayed in Fig. 2.

The protocol involves four steps:

(i) Contrast and Brightness: in the first step, the image is processed to optimize contrast and brightness in order to heighten the pores. The parts of the SEM picture corresponding to very dark areas outside of the specimen are removed to facilitate the treatment (top left panel in Fig. 2(1)).

(ii) Grayscale threshold: in the second step, the image is processed using a low/high threshold filter. This filtering is needed for the automatic edge detection and insures

Table 1

Chemical composition of LFC A319.

\begin{tabular}{|c|c|c|c|c|c|c|c|c|c|c|c|}
\hline Si\% & $\mathrm{Mn} \%$ & $\mathrm{Fe} \%$ & $\mathrm{Mg} \%$ & $\mathrm{Cu} \%$ & Zn\% & $\mathrm{Ti} \%$ & Ni\% & Srppm & Pppm & V\% & Zr\% \\
\hline 7.18 & 0.15 & 0.43 & 0.32 & 3.17 & 0.19 & 0.05 & 0.010 & 0.020 & 0.010 & 0.006 & 0.002 \\
\hline
\end{tabular}


Table 2

Low Cycle Fatigue tests condition summary.

\begin{tabular}{lcll}
\hline Temperature $\left({ }^{\circ} \mathrm{C}\right)$ & Number of tests & $\Delta \varepsilon(\%)$ & Number of cycles to failure \\
\hline 150 & 7 & $0.1-0.6$ & $200-10,000$ \\
200 & 14 & $0.1-0.5$ & $40-16,000$ \\
250 & 14 & $0.1-0.3$ & $100-6000$ \\
\hline
\end{tabular}

accurate morphology measurements. This step should be performed with care in order to distinguish between porosities, inclusions and other possible defects.

(iii) A Feret diameter: the Feret diameter $d_{F}$ is defined as the largest distance between two points lying in a closed curve. In the case of the porosities, the Feret diameter is computed using the contours computed by edge detection defined in the previous steps (see Fig. 1(1)). This diameter is a classic indication of size in terms of particle analysis [36].

(iv) Equivalent ellipse size: finally, for each of the identified porosities, the software calculates an equivalent ellipse (Fig. 2(4)) that has the same area, the same perimeter (so the same circularity) and also the same orientation as the original porosity as seen in Fig. 1(2). The study of this ellipse perigee and apogee is a second information about the pore size.

The results presented next correspond to the study of an area of approximately $\approx 60 \mathrm{~mm}^{2}$ that is analyzed within 8 images (Fig. 3). The studied regions corresponds to the intervalve bridge zone of an automotive cylinder head, which is critical under start-idle-stop TMF loading of the engine. Various statistical information about the porosities are summarized in Table 3 .

Pores with an area smaller than $2 \times 2$ pixels, corresponding to $\approx 60 \mu \mathrm{m}^{2}$ were not taken into account, as their nature could not be properly defined due to the pictures resolution. This rule is in accordance to crack initiation observations. The crack initiation seems indeed to appear closer to substantially larger objects. The maximum area observed here for a porosity is $131,000 \mu \mathrm{m}^{2}$ $\left(\approx 0.13 \mathrm{~mm}^{2}\right)$, which corresponds to an equivalent circle radius of $204 \mu \mathrm{m} \approx 0.2 \mathrm{~mm}$.

\subsection{Porosities distribution}

In this study, 248 pores were detected using the proposed procedure and their Feret diameter or apogee of an equivalent ellipse has been measured. In [30], it has been shown that the pore sizes match a log-normal distribution function expressed as:

$\left.p_{a}=\frac{1}{a \hat{\sigma} \sqrt{2 \pi}} \exp \left[-\frac{1}{2} \frac{\ln (a)-\hat{\hat{\mu}}}{\hat{\sigma}}\right)^{2}\right]$

where $a$ is the pore size. $\hat{\hat{\mu}}$ and $\hat{\sigma}$ denote the mean value and the standard deviation of the distribution, which can be computed for a discrete series of porosities $a_{i}, i=1, n$ using the formulas:
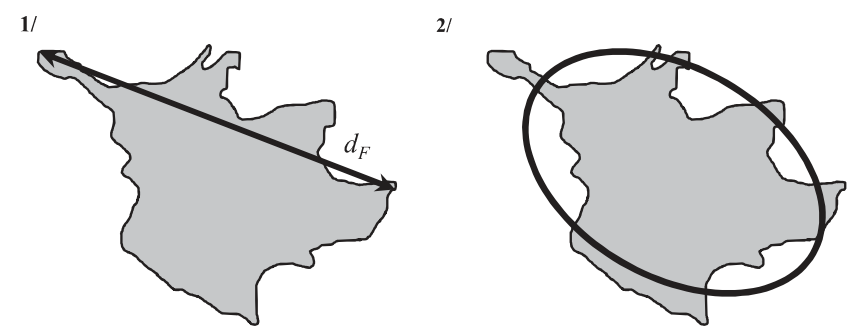

Fig. 1. Feret diameter and equivalent ellipse for a porosity. $\hat{\hat{\mu}}=\frac{1}{n} \sum_{i=1}^{n} \ln \left(a_{i}\right) \quad \hat{\sigma}=\sqrt{\frac{1}{n} \sum_{i=1}^{n}\left(\ln \left(a_{i}\right)-\hat{\hat{\mu}}\right)^{2}}$

A common method to quantify the adequacy with an chosen distribution function is to build a Quantiles-Quantiles plot to compare the observed data set with the model. This method provides a graphical assessment to judge the relevance of a log-normal representation of the data. First, the mean value and standard deviation of the statistical sample are computed using Eq. (2). Second, a random selection of 248 individuals from a log normal distribution with the same mean value and standard deviation are drawn. The comparison between the ordered quantiles of these two samples enables to the comparison and to estimate the "lognormality" of measured pore sizes. Fig. 4(1) displays the results in the case where the pore size is estimated using the Feret diameter (on the Figure, it is more precisely the normality of the logarithm of the sample Feret diameters which is tested). If the experimental data can be statistically described by a log-normal distribution, the set of points of the $\mathrm{Q}-\mathrm{Q}$ plot would appear aligned along a straight line. The graphic $4(1)$ is an acceptable choice, excepting for the lowest and highest values.

The choice of an exponential distribution conducts to a overall better correlation as displayed in Fig. 4(2) (here, real values of the sample Feret diameters are directly used). Let us recall that the expression of the probability density function of an exponential distribution is:

$p(a)=\lambda \exp (-\lambda a)$

The constant $\lambda$ can easily be identified from the 248 experimental observations as it represents the inverse of the mean value of the sample, defined for a discrete series of porosities $a_{i}, i=1, n$ as:

$\lambda=\left(\frac{1}{n} \sum_{i=1}^{n} a_{i}\right)^{-1}$

The parameters characterizing the distribution of porosities for exponential and log-normal distribution are given in Table 4. The values are given for porosity size expressed in terms of the Feret diameter or the apogee of equivalent ellipse. Figs. 5 and 6 display the bins (frequency histograms) for the Feret diameter and the apogee and of equivalent ellipse, respectively, and the corresponding distribution type: exponential and log-normal. The observed pore sizes and the chosen distributions coincide over a large range in the middle range of pore sizes. The errors for large values, are acceptable as a statistical analysis of the parts under discussion showed the bigger porosities rarely occure and can be neglected for design. Furthermore, Figs. 5 and 6 also highlight the different representations given by the exponential and log-normal for very small porosities, which does not influence the results discussed next.

\section{From defects to lifetime}

The distribution of defects in the material, i.e. the distribution of pore size $a$ defined by the Feret diameter or the apogee of an equivalent ellipse, characterizes the resistance of the structure against TMF and is estimated in the previous section using two kinds of probability density functions. Let us further assume that defects will grow to a critical size following a growth-law of the Paris type. The combination of the probability density function of the pore size will be transformed by the growth-law into a probability density function of the number of cycles to failure, provided a critical size representing the failure is also introduced.

In accordance with prior studies for cast aluminum alloys [31,32], let us assume the following deterministic defect growth 
$1 /$

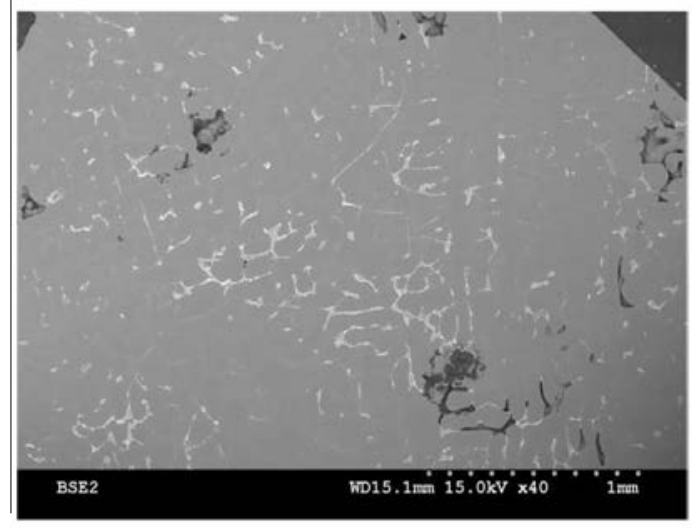

3/

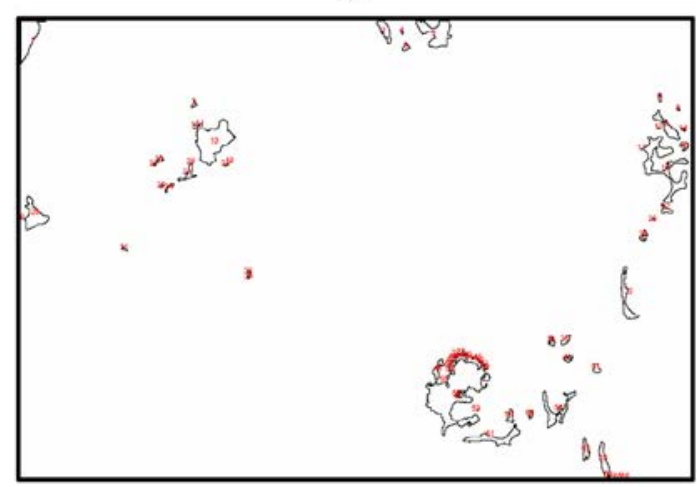

2/

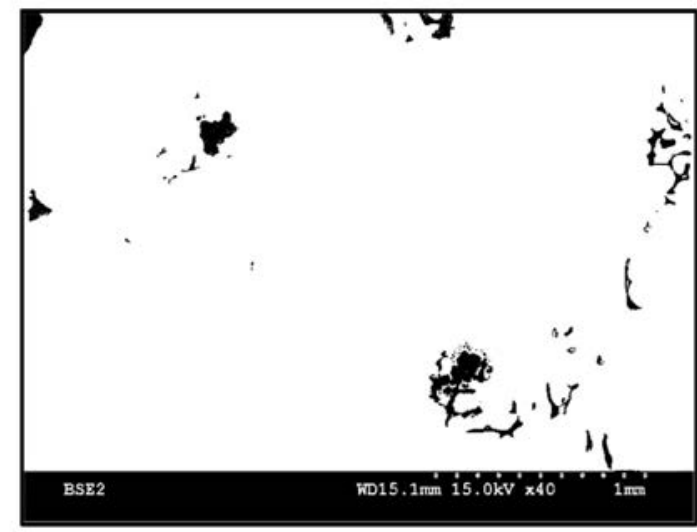

4/

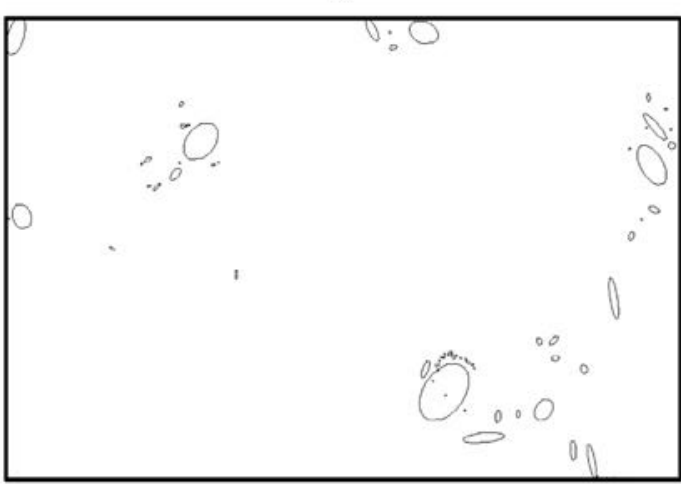

Fig. 2. Image analysis protocol to count pores in A319-LFC alloy.

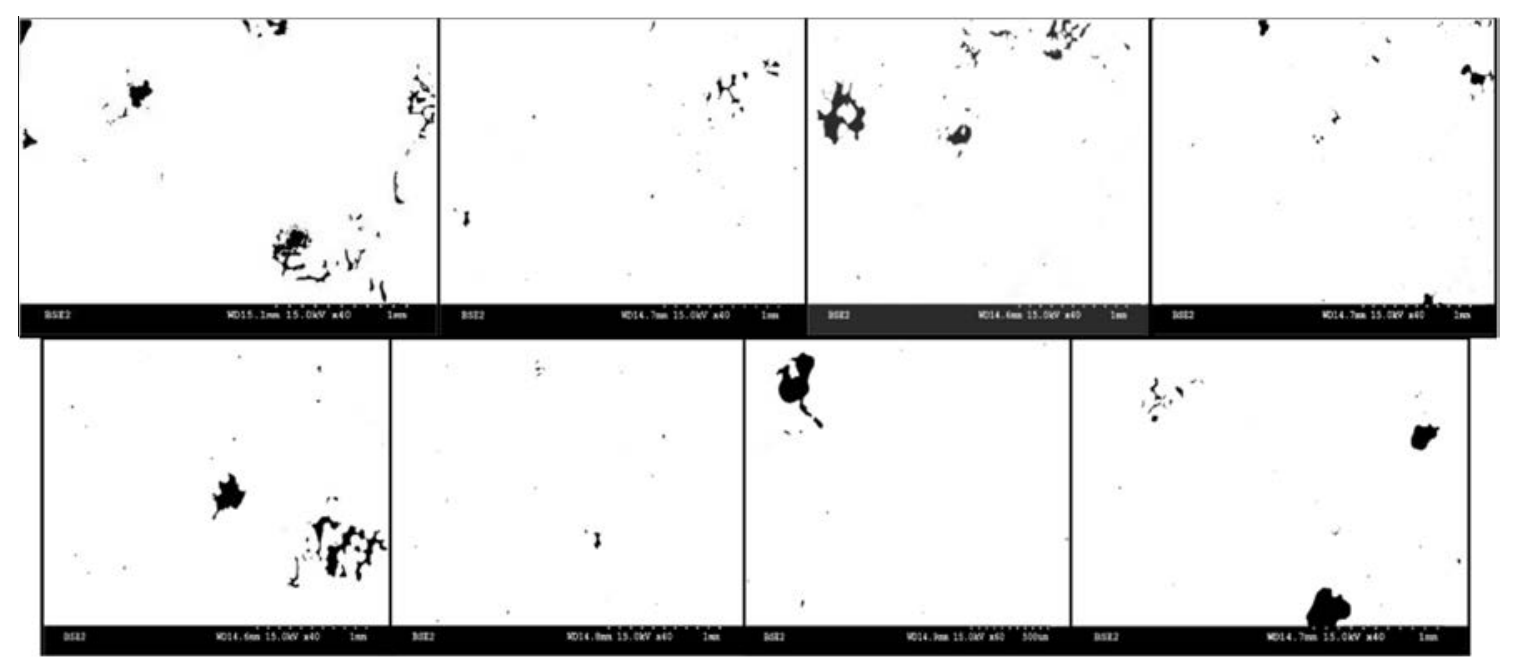

Fig. 3. Pores analysis in the intervalve bridge zone of an automotive cylinder head.

Table 3

Porosities analysis.

\begin{tabular}{lllllll}
\hline $\begin{array}{l}\text { Detected } \\
\text { porosity }\end{array}$ & $\begin{array}{l}\text { Min. } \\
\text { area } \\
\left(\mu \mathrm{m}^{2}\right)\end{array}$ & $\begin{array}{l}\text { Max. } \\
\text { area } \\
\left(\mu \mathrm{m}^{2}\right)\end{array}$ & $\begin{array}{l}\text { Min. } \\
\text { Feret } \\
\text { diameter } \\
(\mu \mathrm{m})\end{array}$ & $\begin{array}{l}\text { Max. } \\
\text { Feret } \\
\text { diameter } \\
(\mu \mathrm{m})\end{array}$ & $\begin{array}{l}\text { Min. } \\
\text { ellipse } \\
\text { apogee } \\
(\mu \mathrm{m})\end{array}$ & $\begin{array}{l}\text { Max. } \\
\text { ellipse } \\
\text { apogee } \\
(\mu \mathrm{m})\end{array}$ \\
\hline 248 & 62 & 131,000 & 7 & 616 & 6 & 453 \\
\hline
\end{tabular}

law, defining the number of cycles to failure $N_{f}$ in terms of a fatigue parameter $\phi$, an initial and a final defect size, $a$ and $a_{f}$ :
$N_{f}=\left(\frac{\phi}{k}\right)^{-m}\left(a^{1-m}-a_{f}^{1-m}\right)$

where $k$ and $m$ are real positive valued parameters with $m$ considered superior to 1 . The initial defect is a pore or an inclusion of size $a$ while the final defect has size $a_{f}$. The final defect is associated with a critical or unacceptable crack for the part under scritinity. The size of a macroscopic crack on a laboratory fatigue test specimen that induces final failure is in $\mathrm{mm}$ size, while on a structure final failures are induced by $\mathrm{cm}$ or $\mathrm{dm}$ size cracks. These values are 

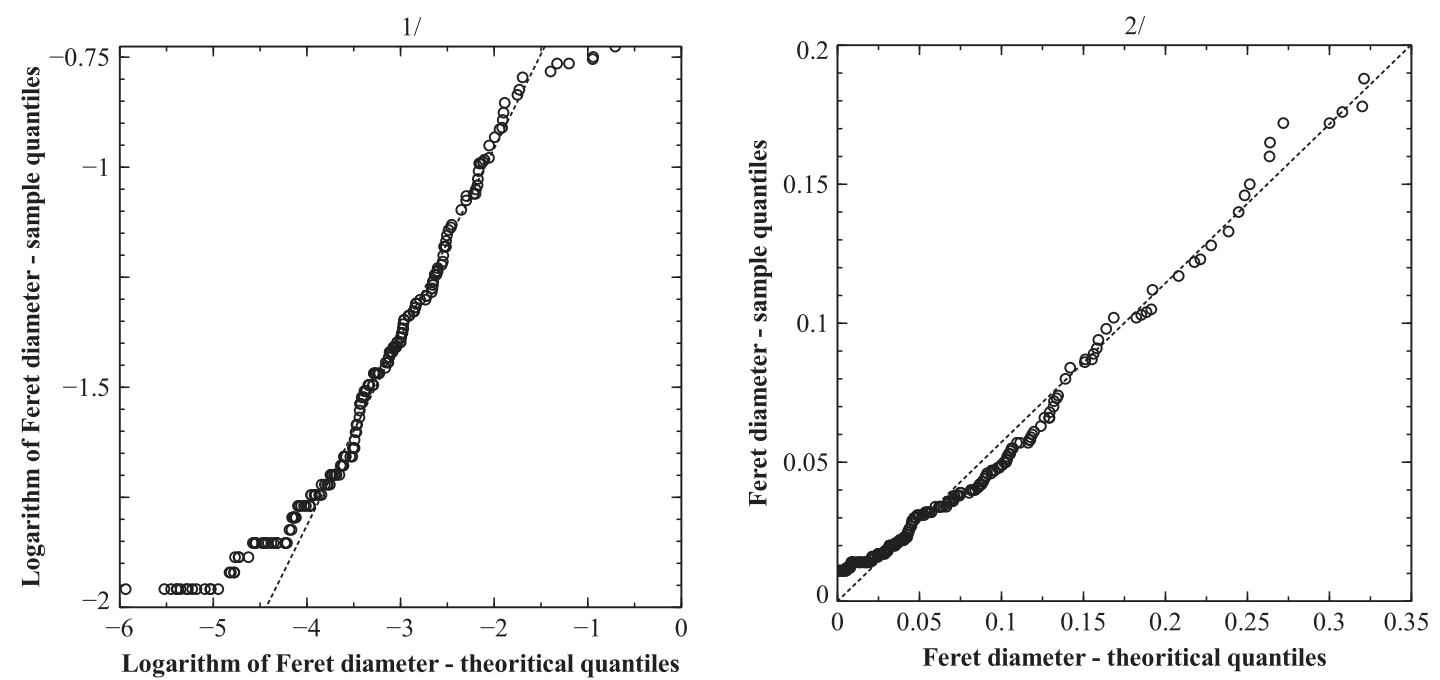

Fig. 4. Quantiles versus Quantiles plot for a lognormal assumption (1) and an exponential assumption (2) in the case of the Feret diameter analysis.

Table 4

Probability density parameters.

\begin{tabular}{lll}
\hline & $\begin{array}{l}\text { Exponential } \\
\text { distribution }\end{array}$ & $\begin{array}{l}\text { Log-normal } \\
\text { distribution }\end{array}$ \\
\hline Feret diameter & $\lambda=23.134$ & $\hat{\sigma}=0.991 ; \hat{\mu}=-3.264$ \\
$\begin{array}{c}\text { Apogee of equivalent } \\
\text { ellipse }\end{array}$ & $\lambda=17.808$ & $\hat{\sigma}=0.415 ; \hat{\mu}=-1.481$ \\
\hline
\end{tabular}

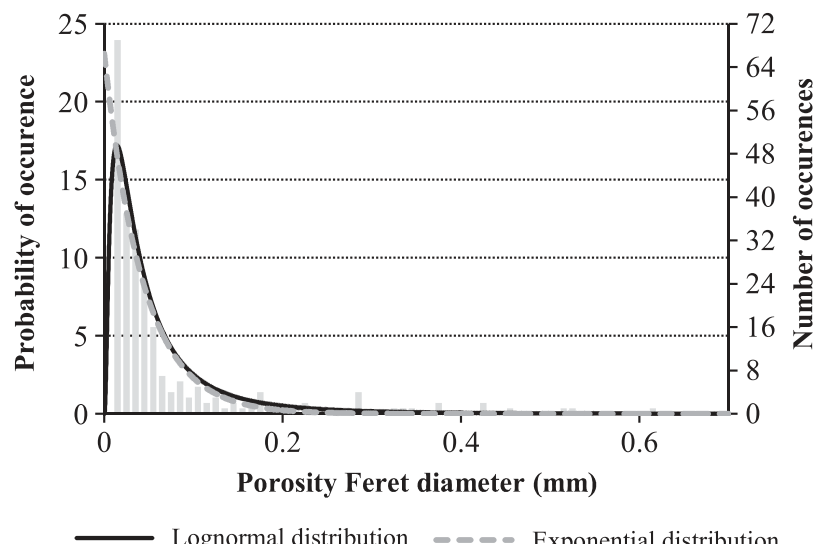

Fig. 5. Histogram of the Feret diameter and the identified exponential and lognormal distributions.

consistent with post-mortem fatigue specimen observations in [33]. In high cycle fatigue studies critical macroscopic crack length was reported 1-2.5 $\mathrm{mm}$ range, depending on the applied stress level [30]. In order to keep a conservative lifting position choose here a final length $a_{f}$ of $1 \mathrm{~mm}$.

Pores are here assumed to be the defects in the microstructure that will create stresses concentration zones favorable to the initiation and propagation of fatigue microcracks. Their size can therefore be used as an estimation of the distribution of initial defect length. This hypothesis seems consistent with observations made on postmortem tested specimens for which one can notice that microcracks are concentrated around porosities just as seen in Fig. 7.

The fatigue parameter $\phi$ in Eq. (5) represents the thermomechanical fatigue loading conditions and is a measure of the

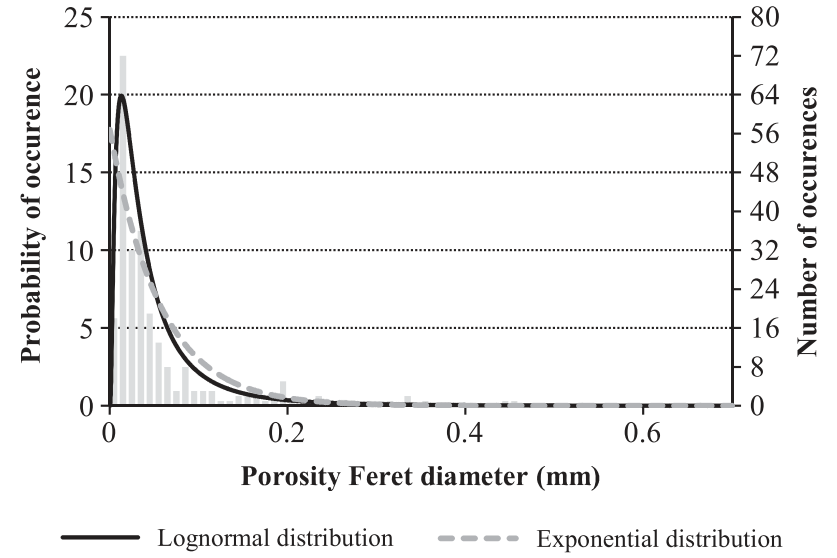

Fig. 6. Histogram of the apogee of the equivalent ellipse and identified exponential and lognormal distributions.

stabilized cycle as defined in [34]. The particular form of $\phi$ used next is the dissipated inelastic energy density per cycle compensated by the maximal hydrostatic stress as defined in $[24,25]$ :

$\phi=\Delta W+\alpha \sigma_{H}^{\max }$

with $\alpha$ a material parameter. We recall that:

$\Delta W=\int_{\text {cycle }} \sigma: \dot{\varepsilon}_{\text {inelastic }} d t$

$\sigma_{H}^{\max }=\max _{\text {cycle }} \frac{1}{3} \operatorname{tr} \sigma$

The efficiency of this fatigue parameter for deterministic lifetime prediction has been discussed for the lost foam aluminum alloys in $[27,29]$ with a good match between calculated and measured lifetime and, in the following, the value of $\alpha$ identified by Tabibian et al. [29] on the A319 aluminum alloy is used. However, this particular choice does not interfere with the generality of the proposed method. For a given damage parameter $\phi$, the expression in Eq. (5) always defines the lifetime $N_{f}$ as a function of $a$, a functional dependence that could be expressed as $N_{f}=\eta(a, \phi)$ and $a=\eta^{-1}\left(N_{f}, \phi\right)$. If the size of the initial defect $a$ is assumed to be represented by a probability density function $p_{a}$, it then follows that 

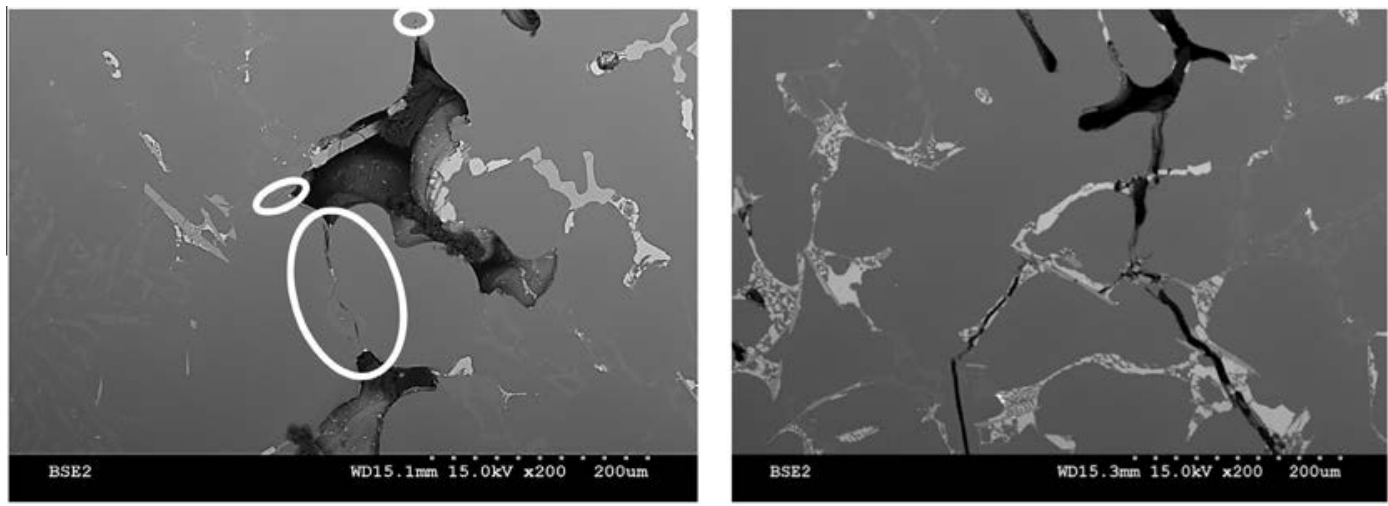

Fig. 7. Fatigue cracks around pores in A319 LCF specimen.

the lifetime (number of cycles to failure) can equally be represented as a probability density function $p_{F}$ with $N_{f}$ as a random variable.

The relation between the probability density functions $p_{a}$ and $p_{F}$ is a change of variables described by:

$p_{F}=\frac{1}{\left|\left(\eta^{-1}\right)^{\prime}\right|} p_{a} \circ \eta^{-1}$

where ' stands for the derivative of the function. The normalization is needed in order to insure that the total measure of the probability is one, i.e. $\int p_{F}=1$.

This relation defines the probability density function of the lifetime as a function of the number of cycles to failure $N_{f}$ as a random variable and the fatigue parameter $\phi$ as a condition. The conditional probability can be expressed as:

$p_{F}=p_{F}\left(N_{f} \mid \phi\right)$

Let us recall that the initial distribution of defect sizes $p_{a}$ is considered as given (log-normal or exponential). If $p_{a}$ has a closed form expression then $p_{F}$ has equally a closed form expression. The mathematical inference of the analytical form of this distribution is presented in Appendix $A$. In the case where $p_{A}$ is lognormal, then $p_{F}$ is equal to:

$$
\begin{aligned}
p_{F}= & \left(\frac{\phi}{k}\right)^{m} \frac{1}{|1-m| \sigma \sqrt{2 \pi}\left[a_{f}^{1-m}+N_{f}\left(\frac{\phi}{k}\right)^{m}\right]^{\frac{1}{1-m}}}\left[a_{f}^{1-m}+N_{f}\left(\frac{\phi}{k}\right)^{m}\right]^{\frac{m}{1-m}} \\
& \times \exp \left[-\frac{1}{2}\left(\frac{\ln \left[a_{f}^{1-m}+N_{f}\left(\frac{\phi}{k}\right)^{m}\right]^{\frac{1}{1-m}}-\hat{\hat{\mu}}}{\sigma}\right)^{2}\right]
\end{aligned}
$$

If $p_{A}$ is exponential then $p_{f}$ takes the following form:

$$
\begin{aligned}
p_{F}= & \frac{\lambda}{|1-m|}\left(\frac{\phi}{k}\right)^{m}\left[a_{f}^{1-m}+N_{f}\left(\frac{\phi}{k}\right)^{m}\right]^{\frac{m}{1-m}} \\
& \times \exp \left[-\lambda\left[a_{f}^{1-m}+N_{f}\left(\frac{\phi}{k}\right)^{m}\right]^{\frac{1}{1-m}}\right]
\end{aligned}
$$

Therefore, the probability density function $p_{F}$ depends directly on the material parameters $m$ and $k$ defining the microcrack growthlaw (see Eq. (5)). These parameters can now be identified from a series of $n$ experimental data pairs: $\left\{\left(N_{f}^{(i)}, \phi^{(i)}\right) \mid i=1, n\right\}$ and the identification can be performed using different methods. Two particular ones have been chosen here:

(i) maximizing likelihood:

$$
(m, k)=\operatorname{argmax} \Pi_{i=1}^{n} p_{F}\left(N_{f}^{(i)}, \phi^{(i)}\right)
$$

which is one of the standard techniques to identify probability density functions from experimental data [35,37]. This optimization allows accessing the values of the $m$ and $k$ parameters without any a priori choice on the criterion form since it is only a maximization of the probability of occurrence of the experimental database. We chose therefore to represent the criterion function - referred as the lifetime line - as the line connecting either the median number of cycles to failure or the maximum probability value for $p_{F}$ to a given fatigue parameter $\phi$.

(ii) minimizing distance between experiments and lifetime line: The fatigue criterion, referred as the lifetime line, is defined here as the locus of most probable lifetime $N_{f}$ for a given fatigue parameter $\phi$. Taking into account maximal property of $p_{F}$ at the most probable lifetime, the locus is defined by the implicit equation:

$$
\frac{\partial p_{F}}{\partial N_{f}}\left(N_{f}, \phi\right)=0
$$

If the solution of this equation is written as $\phi\left(N_{f}\right)$, minimizing the distance conducts to the following least squares problem:

$$
(m, k)=\operatorname{argmin} \sum_{i=1}^{n} \frac{1}{2}\left|\phi^{(i)}-\phi\left(N_{f}\right)^{(i)}\right|^{2}
$$

In this case, the optimization process provides both the unknown parameters $m$ and $k$ of the problem but also the lifetime fine, which is actually the fatigue criterion.

\section{Results and discussion}

A series of fatigue criteria have been identified from an experimental TMF database on over-aged specimens. The criteria have been identified using all possible choices between the discussed options:

(i) pore size measurement: Feret diameter or apogee of equivalent ellipse;

(ii) probability distribution: lognormal or exponential;

(iii) optimization method: maximum likelihood or least-square minimization.

Each of the identified criteria is represented by the same probability distribution given in Eq. (5) but with varying material parameter values for $m$ and $k$. The identified parameters and the corresponding choices in the method are displayed in Table 5.

The results expressed in terms of estimated versus experimental fatigue lifetime (see Figs. 8 or 9 for example) show that the initial choice of probability density function for the pore-size (exponential or lognormal) has a negligible impact on the final 
Table 5

Criterion identification and correlation coefficient.

\begin{tabular}{lllll}
\hline $\begin{array}{l}\text { Image } \\
\text { analysis }\end{array}$ & $\begin{array}{l}\text { Pores } \\
\text { distribution }\end{array}$ & $\begin{array}{l}\text { Optimization } \\
\text { process }\end{array}$ & $\begin{array}{l}\text { Identified } \\
k\end{array}$ & $\begin{array}{l}\text { Identified } \\
m\end{array}$ \\
\hline Feret diameter & Log-normal & Maximum likelihood & 3.929 & 1.765 \\
Feret diameter & Exponential & Maximum likelihood & 4.024 & 1.734 \\
Ellipse apogee & Log-normal & Maximum likelihood & 3.377 & 1.789 \\
Ellipse apogee & Exponential & Maximum likelihood & 4.804 & 1.718 \\
Feret diameter & Log-normal & $\frac{\partial p_{F}}{\partial N_{f}}\left(N_{f}, \phi\right)=0$ & 0.956 & 2.785 \\
& & & & \\
\hline
\end{tabular}

result. A similar observation is valid for the choice of the measure of the pore size (Feret or ellipse apogee).

For a given optimization method of identifying the value of the $k$ and $m$ parameters - the maximum likelihood estimator - only a small value variation has been observed between a log-normal and an exponential distribution for the pores size statistic based on the Feret diameter (see Table 5). Values of the parameters $k$ and $m$ differ by about $2 \%$, which induces only minor differences in terms of average lifetime: an average estimation gap of 49 cycles is recorded for an average numerical lifetime of 1609 cycles for the exponential distribution, i.e. approx. 2\%. Differences are more striking for the distribution of pores size based on the equivalent ellipse apogee in terms of $k$ and $m$ values. In spite of these differences, lifetime estimations stay close together and can be neglected. The two different choices of statistical distributions leads to an estimated lifetimes that differs by 37 cycles for a average lifetime of $1583 \mathrm{cy}$ cles in the case of the exponential distribution, i.e. approx. $2.5 \%$.

The comparison of the different mathematical methods employed is represented in terms of estimated versus measured lifetime in $\log / \log$ plot. The criterion is considered satisfactory, if the predicted number of cycles to failure is between half and double experimental lifetime, denoted at the relevance interval.

The parameters identified by a maximum likelihood did not provide fully satisfactory results. The fatigue criterion build as the locus of median of predicted lifetime distributions delivered the best results. However, even in this case, 10 results out of 35 (29\%) lied outside the relevance interval as displayed in Fig. 8. The criterion built as the locus of maximum probability provides unsatisfactory results as 18 points lie outside the relevance interval (52\%) as displayed in Fig. 9.

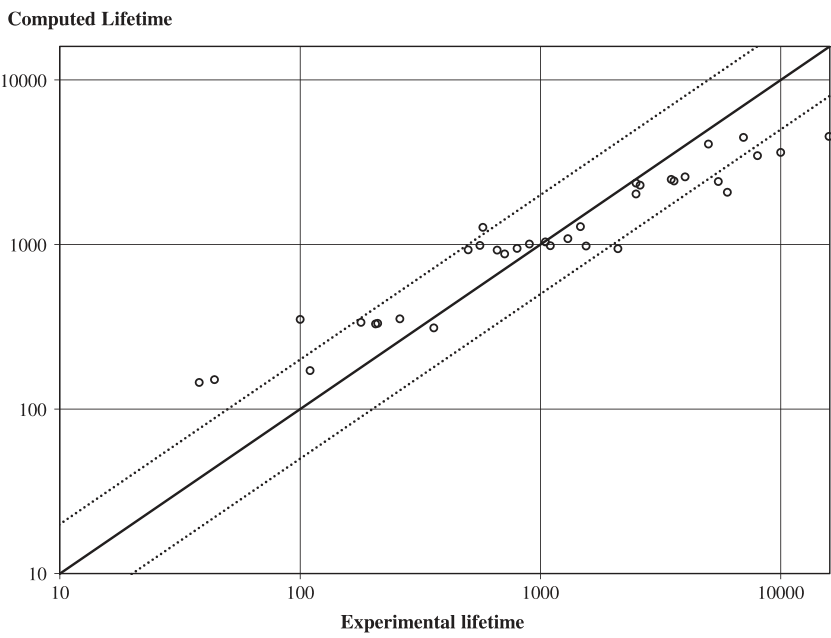

Fig. 8. Computed versus experimental lifetime - Computed values are the median of the lifetime distribution for Feret exponential pores size distribution identification (identification obtained by maximum likelihood).

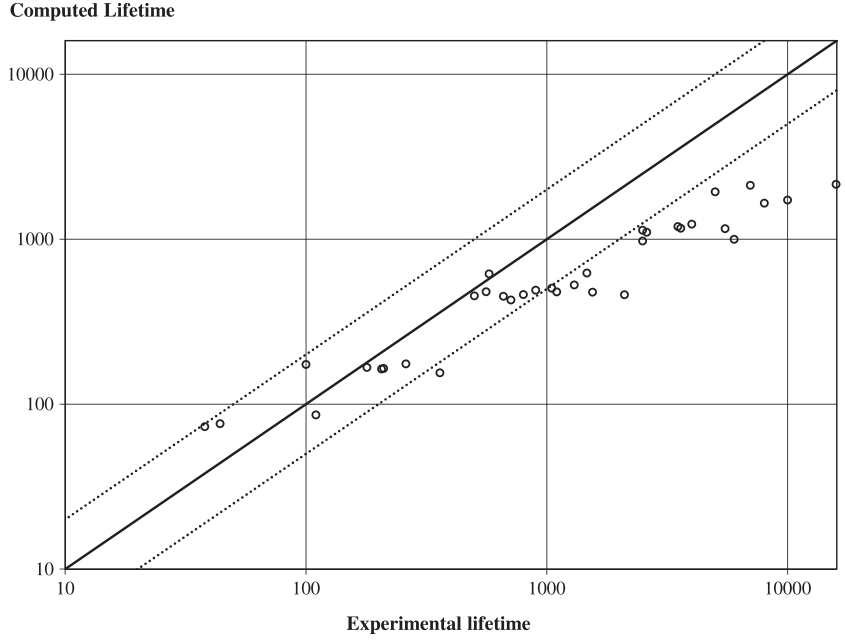

Fig. 9. Computed versus experimental lifetime - Computed values correspond to the maximum probability of the lifetime distribution for Feret exponential pores size distribution (identification obtained by maximum likelihood).

Moreover, as it can be seen in Fig. 12, that these two identified criteria are poorly positioned with respect to the experimental points. We can state that they have a strong tendency to overestimate the lifetime for high values of $\phi$ and underestimate it for lower values of $\phi$. This can be justify, by the a relatively small number for a precise statistical answer (database containing only 35 elements).

As seen in Fig. 10, we observe maximum probability values higher for high values of $\phi$ than for low values of $\phi$ of the fatigue parameter. The standard deviations of the distributions tend to grow for small values of $\phi$, which implies that the tests corresponding to high values of $\phi$ are considered as more important in the maximum likelihood estimation process, i.e. with a higher probability value for which variations would have a more severe impact on the likelihood computation. Moreover, the maximum of the likelihood function is here generally obtained for pairs of parameters $(k, m)$, located in areas where

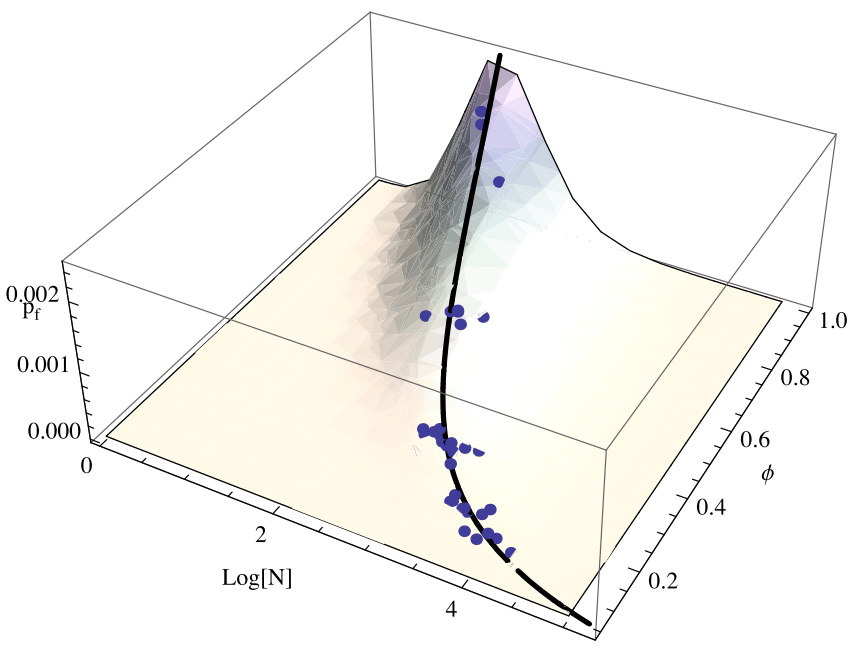

Fig. 10. Lifeline and experimental results observation with the evolution of the probability of failure densities for each value of $\phi$ - Feret exponential pores size distribution (identification obtained by minimizing the distance between experiments and the lifetime line). 


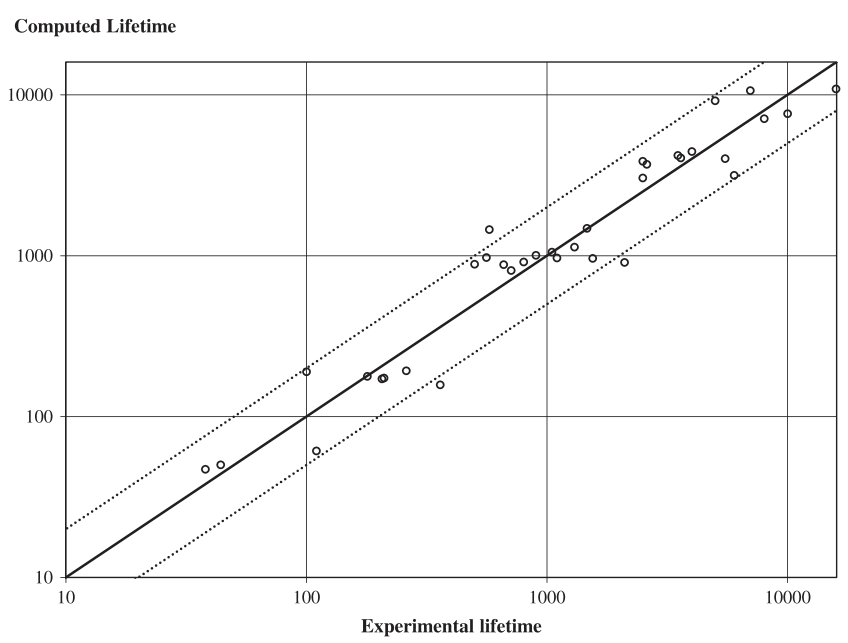

Fig. 11. Computed versus experimental lifetime - Computed values correspond to the maximum probability of the lifetime distribution for Feret exponential pores size distribution (identification obtained by minimizing the distance between experiments and the lifetime line).

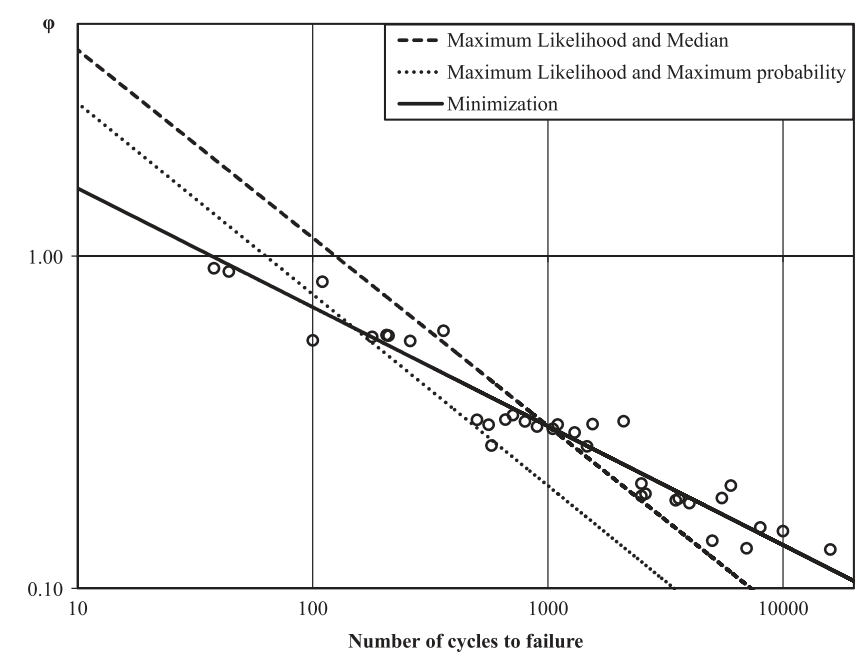

Fig. 12. The criterion lifeline obtained using different mathematical optimization methods: maximum likelihood and median, maximum likehood and maximum probability and least squares minimization.

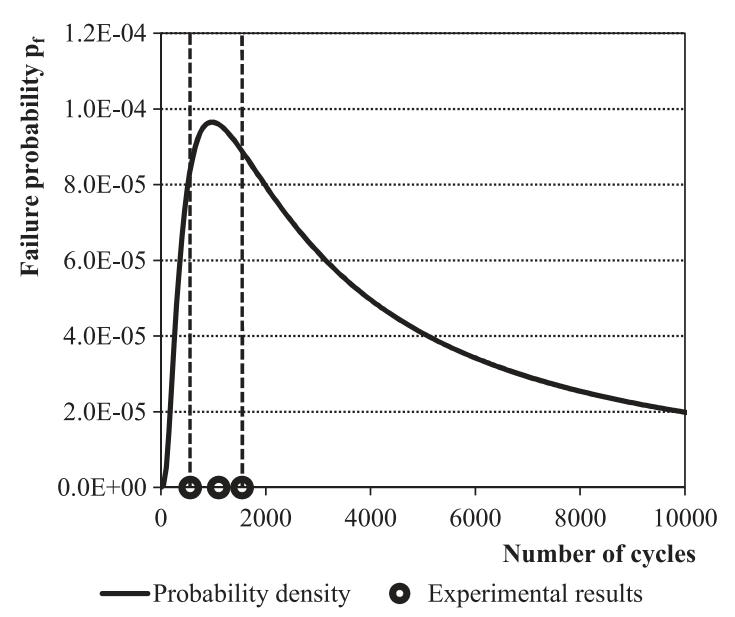

(a) Failure probability the gradient of the likelihood function is close to zero, with a large margin error.

Finally, we can state that the least squares optimization computing the fatigue criterion as the locus of the maximum probability gives the best results. Fig. 11 show that this method keeps only 3 fatigue results out of the relevance interval and provides therefore $92 \%$ of satisfactory results. The least squares method seems to be more appropriate taking into account the size of our experimental basis, as it distributes all the experimental points closer to the maximum probability independent of their value. This good agreement between experience and model is displayed in Fig. 12.

The proposed method supplies the lifetime estimates as effectively as the deterministic criterion proposed for example by Tabibian et al. [27]. However, the additional information in the probability density functions of failure is an important improvement. It is now possible to estimate the variation of the fatigue strength of the material and to compute confidence intervals on the estimated lifetime.

For a fatigue parameter $\phi$ equal to 0.311 , there are three experimental tests that have lifetimes respectively equal to 560,1100 and 1550 cycles. The median lifetime given by the criterion is 11,950 cycles while the most probable lifetime is 950 cycles. In order to interpret the result Let us further remark that the decrease of the probability with the number of cycles is very slow: the probability of failure at 4000 cycles is $4.95 e-5$ while at 10,000 it is $2 \mathrm{e}-5$ and decrease at 30,000 cycle only to $5.4 \mathrm{e}-6$. However an inspection of the cumulative probability function, show that the 50.

Fig. 13 shows that the cumulative failure distribution for this value of the fatigue parameter $\phi$ predicts only a $20 \%$ failure probability between 1 and 2650 cycles or between 2650 and 7250 cycles. On the same figure are equally displayed three lifetimes corresponding to structural tests effectively breaks. One can remark that they lie within the region with a highest failure probability.

The failure probability remains high for large lifetimes, in spite of the observed experimental results. These lifetime correspond to very small defect size, which have not been precisely observed and for which the growth law should be modified in the future.

One can conclude that this measure of the TMF strength is an interesting advancement for the stress-strength reliability analysis of a structure as proposed in [38].

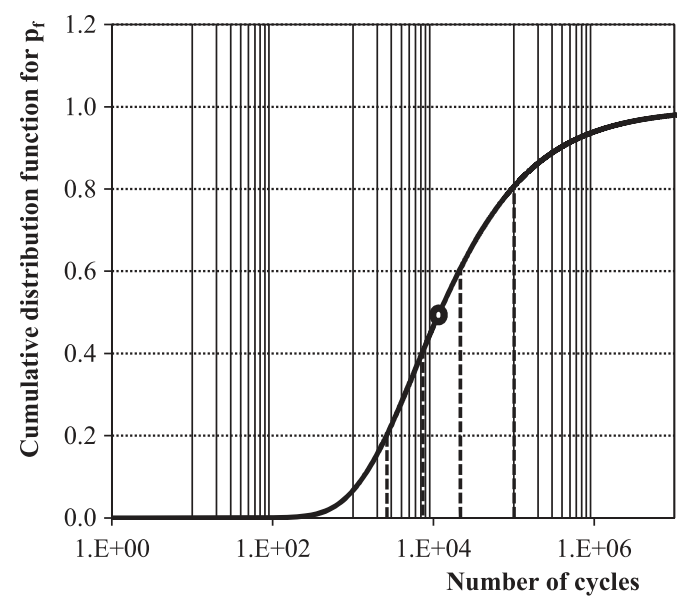

(b) Cummuluative failure probability

Fig. 13. Probability density for a fatigue parameter of $\phi=0.311$ expressed as failure probability and cumulative failure probability in panels (a) and (b) respectively. 


\section{Conclusions}

This paper proposes a novel method to estimate the probability density distributions of thermomechanical fatigue lifetime, based on the estimation of defects probability density throughout the analysis of SEM images. For an A319 lost foam casted aluminum alloy, pores are identified as the most serious defects for thermomechanical fatigue. Log normal or exponential distributions give a good representation of the variability of the pore size, represented by their Feret diameter. A lifetime probability density function is proposed thanks to a criterion involving a fatigue parameter $\phi$, representative of the TMF loading condition (inelastic energy density dissipated per cycle combined with the maximal hydrostatic pressure) and a crack growth law. The criterion parameters are optimized to have the estimated lifetimes that match with the experimental observations. The proposed criterion provided predictive results for the studied A319 aluminum alloy used for automotive cylinder heads while lifetime probability are explicitly computed to be used as an input to a stress-strength interference method.

The model discussed is based on a series of material assumptions, i.e. type and shape of defects and their evolution law during cycling, which have to be adapted each time the method is extended towards a class of materials. However, fatigue life of several classes of materials cannot be analyzed using this framework, as for example materials failing just under cyclic loading of transgranular slip bands. In this cases new ways of including a material variability have to be imagined.

\section{Acknowledgements}

The authors would like to thank David Balloy, Jean-Yves Dauphin and Jean-Charles Tissier at the Ecole Centrale de Lille, France, for their help in SEM analysis and fruitful discussion during this work; Alexandra Marie-Louise (PSA Peugeot-Citroen) for providing the experimental database. This work was supported by PSA Peugeot-Citroen and has received the financial support of the French Minister of Research and Higher Education and of the project ANR-12-RMNP-0011.

\section{Appendix A. Closed form solutions for the probability density functions}

$p_{N \mid \Delta W+\alpha \sigma_{h}^{\max }}(n)=p_{\text {pores sizes }}(s)\left|\frac{\partial s}{\partial n}\right|$

Introducing $s$ as the initial pore size in the Eq. (5):

$n=\left(\frac{\Delta W+\alpha \sigma_{h}^{\max }}{\gamma}\right)^{\frac{-m}{2}}\left(s^{1-\frac{m}{2}}-a_{f}^{1-\frac{m}{2}}\right)$

$s=\left[n\left(\frac{\Delta W+\alpha \sigma_{h}^{\max }}{\gamma}\right)^{\frac{m}{2}}+a_{f}^{1-\frac{m}{2}}\right]^{\frac{2}{2-m}}$

and consequently:

$\frac{\partial s}{\partial n}=\frac{2}{2-m}\left[n\left(\frac{\Delta W+\alpha \sigma_{h}^{\max }}{\gamma}\right)^{\frac{m}{2}}+a_{f}^{1-\frac{m}{2}}\right]^{\frac{m}{2-m}}\left(\frac{\Delta W+\alpha \sigma_{h}^{\max }}{\gamma}\right)^{\frac{-m}{2}}$

which gives us:

$$
\begin{aligned}
p_{N \mid \Delta W+\alpha \sigma_{h}^{\max }}(n)= & \frac{2 \lambda}{2-m}\left[n\left(\frac{\Delta W+\alpha \sigma_{h}^{\max }}{\gamma}\right)^{\frac{m}{2}}+a_{f}^{1-\frac{m}{2}}\right]^{\frac{m}{2-m}}\left(\frac{\Delta W+\alpha \sigma_{h}^{\max }}{\gamma}\right)^{\frac{-m}{2}} \\
& \times \exp \left(-\lambda\left[n\left(\frac{\Delta W+\alpha \sigma_{h}^{\max }}{\gamma}\right)^{\frac{m}{2}}+a_{f}^{1-\frac{m}{2}}\right]^{\frac{2}{2-m}}\right)
\end{aligned}
$$

\section{References}

[1] Gruzleski JE, Closset BM. The treatment of liquid aluminum-silicon alloys. Des Plaines (IL): American Foundrymen's Society Inc.; 1990.

[2] Hatch JE. Aluminum: properties and physical metallurgy. Metals Park $(\mathrm{OH})$ : American Society for Metals; 1984.

[3] MoustafaFA MA, Samuek FH, Doty HW, Valtierra S. Effect of solution heat treatment and additives on the microstructure of Al-Si A413.1 automotive alloys. Int J Cast Met Res 2002;14:235.

[4] Nagayoshi T, Kodaira T. Analysis of thermal fatigue cracks in cylinder heads. JSAE Rev 1993;14(2):56-60.

[5] Smith T, Maier H, Sehitoglu H, Fleury E, Allison J. Modelling high-temperature stress-strain behavior of cast aluminum alloys. Met Mater Trans 1999;30A: $133-46$.

[6] Thomas JJ, Verger L, Bignonnet A, Charkaluk E. Thermomechanical design in the automotive industry. Fatigue Fract Eng Mater Struct 2004;27: 887-95.

[7] Fischersworring-Bunk A, Thalmair S, Eibl M, Kunst M, Dietsche A. High temperature fatigue and creep automotive power train application perspectives. Mater Sci Technol 2007:23:1389-95.

[8] Albonetti R. Porosity and intermetallic formation in lost foam casting of a356 alloy. Master's thesis. The University of Western Ontario; February 2000.

[9] Gupta M, Lavernia EJ. Effect of processing on the microstructural variation and heat-treatment response of a hypereutectic Al-Si alloy. J Mater Process Technol 1995;54:261.

[10] Campbell J. The concept of net shape for castings. Mater Des 2000;21:373.

[11] Weick M, Aktaa J. Microcrack propagation and fatigue lifetime under nonproportional multiaxial cyclic loading. Int J Fatigue 2003;25:1117-24.

[12] Yamauchi M, Ohtani T, Takahashi Y. Thermomechanical fatigue behavior of materials. Second volume, ASTM STP 1623, chapter thermal fatigue behavior of a SUS304 pipe under longitudinal cyclic movement of axial temperature distribution. ASTM; 1996.

[13] Zouani A, Bui-Quoc T, Bernard M. Fatigue life parameter for type 304 stainless steel under biaxial-tensile loading at elevated temperature. J Eng Mater Technol 1999;121:305-12.

[14] Socie DF. Multiaxial fatigue damage models. Trans ASME J Eng Mater Technol $1987 ; 109(4): 293-8$.

[15] Fatemi A, Socie DF. A critical plane approach to multiaxial fatigue damage including out-of-phase loading. Fatigue Fract Eng Mater Struct 1988;11: 149-65.

[16] Sehitoglu H, Foglesong T, Maier HJ. Precipitate effects on the mechanical behavior of aluminum copper alloys Part I: experiments. Met Mater Trans 2005;36A:749-61.

[17] Nicouleau E, Feyel F, Quilici S, Cailletaud G. Structural calculation and lifetimeprediction in thermomechanical fatigue of engine components. In: Rmy L, Petit $\mathrm{J}$, editors. Temperature-fatigue interaction international conference on temperature-fatigue interaction, ninth international spring meeting. European structural integrity society, vol. 29. Elsevier; 2002. p. 331-40.

[18] Verger L, Constantinescu A, Charkaluk Eric. Thermomechanical fatigue design of aluminium components. In: Temperature-fatigue interaction, Paris; 29-31 May 2001.

[19] Thalmair S, Thiele J, Fischersworring-Bunk A, Ehart R, Guillou M. Cylinder heads for high power gasoline engines-thermomechanical fatigue life prediction. SAE technical paper; 2006. p. 01-0541.

[20] Park J, Nelson D. Evaluation of an energy-based approach and a critical plane approach for predicting constant amplitude multiaxial fatigue life. Int J Fatigue 2000;22:23-39.

[21] Amiable S, Chapuliot S, Constantinescu A, Fissolo A. A computational lifetime prediction of a thermal shock experiment. Part I: thermomechanical modelling and lifetime prediction. Fatigue Fract Eng Mater Struct 2006; 29(3):175-82.

[22] Amiable S, Chapuliot S, Constantinescu A, Fissolo A. A computational lifetime prediction of a thermal shock experiment. Part II: discussion on difference fatigue criteria. Fatigue Fract Eng Mater Struct 2006;29(3):219-27.

[23] Amiable Sebastien, Chapuliot Stephane, Constantinescu Andrei, Fissolo Antoine. A comparison of lifetime prediction methods for a thermal fatigue experiment. Int J Fatigue 2005;28:692-706.

[24] Fissolo A, Amiable S, Ancelet O, Mermaz F, Stelmaszyk JM, Constantinescu A et al. Crack initiation under thermal fatigue: an overview of CEA experience. Part I: thermal fatigue appears to be more damaging than uniaxial isothermal fatigue. Int J Fatigue 2009;31(7):587-600.

[25] Fissolo A, Gourdin C, Ancelet O, Amiable S, Demassieux A, Chapuliot S, et al. Crack initiation under thermal fatigue: an overview of CEA experience: Part II (of II): application of various criteria to biaxial thermal fatigue tests and a first proposal to improve the estimation of the thermal fatigue damage. Int J Fatigue 2009:31(7):1196-210.

[26] Guillot I, Barlas B, Cailletaud G, Clavel M, Massinon D. Thermomechanical fatigue and aging of cast aluminium alloy: a link between numerical modelling and microstructural approach. Eur Struct Integr Soc 2002;29:75-84.

[27] Tabibian S, Charkaluk E, Constantinescu A, Szmytka F, Oudin A. TMF criteria for lost foam casting aluminum alloys. Fatigue Fract Eng Mater Struct 2013;36(4):281-374.

[28] Tabibian Shadan, Charkaluk Eric, Constantinescu Andrei, Oudin Alexis, Szmytka Fabien. Behavior, damage and fatigue life assessment of lost foam 
casting aluminum alloys under thermo-mechanical fatigue conditions. Procedia Eng 2010;2(1):1145-54 [Fatigue 2010].

[29] Tabibian S, Charkaluk E, Constantinescu A, Szmytka F, Oudin A. TMF-LCF lifetime assessment of a foam casting a319 aluminium alloy. Int J Fatigue 2013;53(8):75-81.

[30] Yi JZ, Gao YX, Lee PD, Lindley TC. Statistical modeling of microstructure and defect population effects on the fatigue performance of cast A356-T6 automotive components. Metall Trans A 2006;37:301311.

[31] Caton MJ, Jones JW, Boileau JM, Allison JE. The effect of solidification rate on the growth of small fatigue cracks in a cast 319-type aluminum alloy. Metall Trans A 1999;30:3055-68.

[32] Li Z, Samuel AM, Samuel FH. Effect of alloying elements on the segregation and dissolution of CuAl2 phase in Al-Si-Cu 319 alloys. J Mater Sci 2003;38: 1203-18.
33] Tabibian Shadan. Contributions to thermomechanical fatigue, criteria for los foam casting aluminum alloys. PhD thesis. Palaiseau (France): Ecole Polytechnique; 2011.

[34] Constantinescu A, Charkaluk E, Lederer G, Verger L. A computational approach to thermomechanical fatigue. Int J Fatigue 2004;26:805-18.

[35] Fisher RA. On the mathematical foundations of theoretical statistics. Philos Trans Roy Soc Lond Ser A 1922.

[36] Merkus HG. Particle size measurements: fundamentals, practice, quality Springer; 2009.

[37] Aldrich J, Fisher RA. The marketing of maximum likelihood. Stat Sci 1997;12: $162-76$

[38] Szmytka Fabien, Oudin Alexis. A reliability analysis method in thermomechanical fatigue design. Int J Fatigue 2013;53(8):82-91. 